\title{
Bond behavior between BFRP bar and recycled aggregate concrete reinforced
}

\author{
with basalt fiber
}

\author{
Huaxin Liu*, Jianwei Yang, Xuezhi Wang \\ Civil Engineering and Architecture College of Liaoning University of Technology, Jinzhou, Liaoning 121000, China
}

\begin{abstract}
This study investigated the effect on the bond behavior between BFRP bars and recycled aggregate concrete (RAC), which a total of 54 specimens for pull-out test and 162 specimens for mechanical properties were conducted. The parameters including RAC strength grade, chopped basalt fiber volume content and length, based on orthogonal test the bond stress-slip constitutive were proposed. According to the main results of experiment, the strength of RAC was higher than the other two factors in the effect of mechanical performance and ultimate bonding stress. Similarly, the influence of these factors on the free end slip that the length of chopped basalt fiber was the weakest, then the chopped basalt fiber volume percent was higher compared to RAC strength grade. Application of non-liner regression analysis in the bond stress-slip constitutive relationship with the experimental results and referred to the engineering practice.
\end{abstract}

Keywords: BFRP rebar; recycled aggregate concrete; the pull-out experiments; bond stress-slip relationship; the multiple nonlinear regression model

\section{Introduce}

In resent decades, the recycled concrete aggregates (RCA) were produced by demolition waste which were used to replace the nature aggregate in concrete structures [1] and regarded the results of recent LCA analyses conducted about the life cycle of natural and recycled aggregates [2-3]. RAC was used to reduce energy consumption and available natural resources consumption, thus solving some of the problems in construction engineering. However, some limitation was still existed which made people reluctant to use the RAC in constrictions. The main problem with high water absorption capacity and inside macro cracks that RCA in structural concrete, which leading to decrease in the mechanical properties of concrete.

Fiber reinforced polymer has good chemical stability, thermal stability, resistance to acid and alkali, electric insulation, corrosion, high temperature resistance and other properties. Existing researches showed that chopped fiber reinforced concrete has been widely applied in the field of hydraulic engineering, building construction, highway and other projects for its excellent tensile strength, bonding strength and crack resistance ability, impact resistance properties and excellent impermeability, frost resistance and other properties [3-7]. In addition, FRP bars were used to replace steel rebar in structures to solve the corrosion problem effectively [8-9].

In recent years, a lot of researches about FPR by many scholars had been made. In 1991, Pleimann [10] first proposed the calculation formula about anchorage length of GFRP bar. Ehsani, et al. [11] had studied anchorage length, concrete strength, cover thickness, diameter of FRP reinforcement effect on bond behavior based on 102 static loading tests of GFRP tendons, and derived the calculation formula of GFRP reinforcement anchorage length with hook or without hook. Roman and Robert [12] researched the bonding strength of AFRP reinforcement with concrete according to the center pullout test. Tests results showed that bond strength of AFRP reinforcement was $40 \%-100 \%$ of ordinary steel bar.

* Corresponding author.

E-mail address: 1gliuhuaxin@163.com (H. Liu). 
$\mathrm{Xu}$ et al. [13] studied bond behavior between deformed bars and steel-pp hybrid fiber reinforced concrete, and experimental results showed that the ultimate bonding strength raised $18.4 \%, 17.4 \%$ and $50.5 \%$ and the peaking slip raised $39 \%, 38 \%$ and $31 \%$ respectively with the increasing of the steel fiber volume ratio, steel-fiber long-diameter ratio and concrete strength .

Xue et al. [14] studied the bond performance among 4 different bond mediums with composite reinforced AFRP through 48 standard tension strength tests. Experimental studies had shown that the bond strength of AFRP reinforcement with concrete was about 0.79-1.11 times more than the bond strength of deformed bar, higher around $10 \%$ for it compared to the high performance concrete. In addition, bond strength of AFRP reinforcement with epoxy resin was higher and AFRP reinforcement with cement was low.

Yazcizi et al. [15] had studied the bond behavior of deformed bars and concrete due to steel fiber volume by pullout test. Four variables each concrete series, steel fiber content, length-diameter ratio, concrete strength and cover thickness were prepared. The results of test showed that the bonding strength which was higher $7 \%-16 \%$ for mixing the fiber compared to without fiber. All mechanical properties of fiber reinforced concrete increased as the factors increased, and with great effect of length-diameter ratio 80 comparing to length-diameter ratio 40.

Mazaheripour et al. [16] investigated bond behavior between steel fiber reinforced self-compacting concrete and GFRP bars by 36 pull-out tests. The factors were the diameter of GFRP reinforcement, surface characteristics of GFRP reinforcement, bond-anchorage length, and self-compacting concrete cover thickness. Test results showed that most of the specimens failure mode were the pullout failure, and bond length, cover thickness both affected its bonding strength in a lager degree. Different surface characteristics of GFRP tendons performed the different failure modes ultimately.

Ganesan et al. [17] researched the bond constitutive relation of hybrid fiber reinforced high performance concrete and steel bar through pullout test.
Tests showed that when the steel fiber volume content was $1 \%$ and polypropylene fiber volume content was $0.1 \%$, the corresponding bond strength was the maximum.

At present, current research focuses on bonding properties between ordinary concrete and FRP bars, but the research of basalt fiber recycled concrete with BFRP bar bonding properties is almost none. In this paper, performance of bonding studied by pull-out test and non-linear regression model was used to study stress bond-slip constitutive.

CFRP and GFRP bars reinforced concrete have been studied [18-20]. However, research on the more cheap BFRP bars were limited.

Bond performance was one of the most important requirements in reinforced concrete constructions which determine the cooperatively ability between reinforcement and concrete matrix. Therefore, evaluating that bond behavior between the BFRP bar and RAC matrix was an essential requirement when employing RAC structures.

This paper investigated the effect on the mechanical properties of fiber RAC and bond-slip behavior between BFRP bars and fiber recycled concrete when different fiber content $(0 \%, 0.2 \%, 0.3 \%$ and $0.4 \%$ ) and fiber length $(6 \mathrm{~mm}, 12 \mathrm{~mm}$ and $18 \mathrm{~mm})$. For the recycled coarse aggregates which were applied to three different concrete grades (C40, C50 and C60). The study focused on the influence of different recycle d concrete grade, fiber contents and different length of fiber RAC performance according to the orthogonal tes t.

\section{Experimental Programs}

\subsection{Materials}

The recycled aggregate concrete(RAC) was made up of cement, fly ash, fine aggregate, recycled coarse aggregate, water and additive. The BoHai-brand P.0 42.5 cement was used in this test. Fly ash (Grade II) was used to improve the performance of the RAC. The fine aggregate in the experiment came from the Ling river in JinZhou, and its bulk density was $1.6 \mathrm{~g} / \mathrm{cm}^{3}$ and apparent density was $2.7 \mathrm{~g} / \mathrm{cm}^{3}$, fineness modulus was 2.46. Recycled coarse aggregate was derived from 
abandoned building concrete (the original strength grade of the concrete was $\mathrm{C} 30, f_{c}^{\prime}=34.2 \mathrm{MPa}$ ). The basic properties of coarse aggregates were based on the "Standard for technical requirements and test method of sand and crushed stone (or gravel) for ordinary concrete" (JGJ 52-2006) and shown in Table 1. The water reducing rate of the water reducing agent (poly carboxylic acid, PCA) was 35\%. The cement, fly ash, fine aggregate and recycled coarse aggregate were dry mixed in the cement mix in the first. Then, the PCA water reducing agent was diluted in half of the sample's water allotment and the resulting solution was gradually added to the dry mix in the running spiral stirrer. Finally, the blended chopped basalt fiber and remaining water were then gradually mixing the dry mix manually. Four kind of RAC grades were considered (C40, C50, C60), and the mixes proportion of concrete were shown in Table 2.

The relevant indexes of the chopped basalt fibers (see Fig.1), as well as BFRP bars (see Fig.2) are shown in Table 3 and Table 4.

\section{Table 1}

Basic mechanical properties of recycled aggregates

\begin{tabular}{|c|c|c|c|c|c|c|}
\hline Aggregate type & $\begin{array}{c}\text { Particle size } \\
\text { range } \\
/ \mathrm{mm}\end{array}$ & $\begin{array}{l}\text { Bulk density } \\
\qquad /\left(\mathrm{kg} / \mathrm{m}^{3}\right)\end{array}$ & $\begin{array}{l}\text { Apparant } \\
\text { density } \\
/\left(\mathrm{kg} / \mathrm{m}^{3}\right)\end{array}$ & $\begin{array}{c}\text { Water } \\
\text { absorption } \\
/ \%\end{array}$ & $\begin{array}{c}\text { Crushing } \\
\text { indicators } \\
1 \%\end{array}$ & $\begin{array}{c}\text { silt content } \\
1 \%\end{array}$ \\
\hline Recycled coarse aggregate & $5-20$ & 1400 & 2600 & 3.8 & 18.1 & 0.2 \\
\hline
\end{tabular}

Table 2

Mixing proportions of recycled aggregate concrete

\begin{tabular}{ccccccc}
\hline Mix design & $\begin{array}{c}\text { Cement } \\
\left(\mathrm{kg} / \mathrm{m}^{3}\right)\end{array}$ & $\begin{array}{c}\text { Fine } \\
\text { aggregate } \\
\left(\mathrm{kg} / \mathrm{m}^{3}\right)\end{array}$ & $\begin{array}{c}\text { Recycled coarse } \\
\text { aggregate }\left(\mathrm{kg} / \mathrm{m}^{3}\right)\end{array}$ & $\begin{array}{c}\text { Fly } \\
\text { ash }\left(\mathrm{kg} / \mathrm{m}^{3}\right)\end{array}$ & $\begin{array}{c}\text { Water educing } \\
\text { agent }\left(\mathrm{kg} / \mathrm{m}^{3}\right)\end{array}$ & $\begin{array}{c}\text { Water } \\
\left(\mathrm{kg} / \mathrm{m}^{3}\right)\end{array}$ \\
\hline C40 & 378 & 618 & 1052 & 162 & 2.16 & 190 \\
C50 & 362 & 733 & 1099 & 90 & 1.81 & 163 \\
C60 & 414 & 625.68 & 1112.32 & 138 & 2.208 & 160 \\
\hline
\end{tabular}

\section{Table 3}

The performance metrics of chopped basalt fiber yarn

\begin{tabular}{|c|c|c|c|c|c|c|c|}
\hline $\begin{array}{l}\text { Diameter } \\
/ \mu \mathrm{m}\end{array}$ & $\begin{array}{l}\text { Density } \\
/ \mathrm{g} / \mathrm{cm}^{3}\end{array}$ & $\begin{array}{c}\text { Tensile strength } \\
\text { /Mpa }\end{array}$ & $\begin{array}{c}\text { Elongation at } \\
\text { break } / \%\end{array}$ & $\begin{array}{c}E \\
/ \mathrm{Gpa}\end{array}$ & $\begin{array}{c}\text { Maximum } \\
\text { applicable } \\
\text { temperature } \\
/{ }^{\circ} \mathrm{C}\end{array}$ & Fiber type & $\begin{array}{l}\text { Length } \\
/ \mathrm{mm}\end{array}$ \\
\hline 13 & $2.65 \sim 3.05$ & $3000 \sim 3500$ & 3.2 & $90 \sim 110$ & 650 & Chopped & $6 、 12,18$ \\
\hline
\end{tabular}

\section{Table 4}

The basic performance indexes of BFRP bar

\begin{tabular}{cccccc}
\hline Name & $\begin{array}{c}\text { Diameter } \\
/ \mathrm{mm}\end{array}$ & $\begin{array}{c}\text { Area } \\
/ \mathrm{mm}^{2}\end{array}$ & Tensile strength $/ \mathrm{MPa}$ & $\begin{array}{c}E \\
/ \mathrm{GPa}\end{array}$ & Density $/ \mathrm{g} / \mathrm{cm}^{3}$ \\
\hline BFRP bars & 16 & 201 & 1123 & 51.3 & 1.94 \\
\hline
\end{tabular}




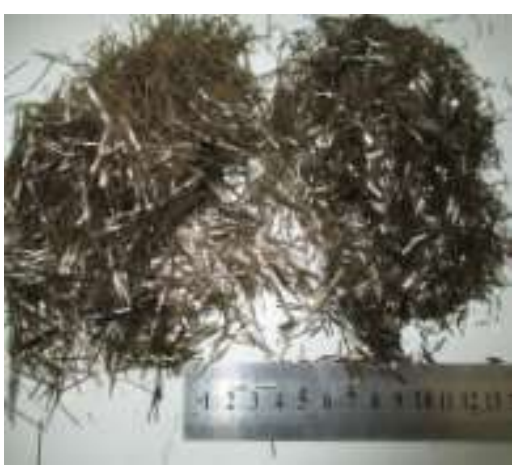

Fig.1. Chopped yarn of basalt fiber

\subsection{Test Design}

In order to explore the influencing factors of the bond performance between RAC and BFRP bar, the method of orthogonal test method was used in this paper. The parameters and values of orthogonal test were shown in Table 5. A total of 9 group of fiber reinforced RAC specimens was designed (specimens named K1-K9), which considered three factors such as the grade of RAC (A), the fiber volume quantities (B),

Table 5

Factors of orthogonal test

\begin{tabular}{cccc}
\hline \multirow{2}{*}{ Test case } & \multicolumn{2}{c}{ Factors } \\
\cline { 2 - 4 } & $\begin{array}{c}\text { A ( Grade of fiber } \\
\text { recycled concrete } / \mathrm{MPa})\end{array}$ & $\begin{array}{c}\text { B (The volume content of } \\
\text { basalt fiber / \% })\end{array}$ & $\begin{array}{c}\text { C (The length of fiber } \\
\text { chopped yarn } / \mathrm{mm})\end{array}$ \\
\hline 1 & C40 & 0.2 & 6 \\
2 & C50 & 0.3 & 12 \\
3 & C60 & 0.4 & 18 \\
\hline
\end{tabular}

\subsection{Specimens}

At present, there is no standard test procedure for fibers cooperated RAC. For each mix, three $150 \mathrm{~mm}$ cubic specimens and prism specimens with $150 \mathrm{~mm} \times 150 \mathrm{~mm}$ in cross section and $300 \mathrm{~mm}$ in height were casted in steel moulds and demoulded, marked and once again transferred to the curing room which was set at $20 \pm 2{ }^{\circ} \mathrm{C}$ with approximately $95 \%$ humidity. The prismoids were used to determine the tensile splitting strength $\left(\mathrm{f}_{\mathrm{ct}}\right)$, and the cubic specimens were used to determine the compressive strength $\left(f_{c, c u b}\right)$ at 28 days. The specimens were produced and maintained, and after a period of 28 days according to standard methods, the mechanical properties of the specimens

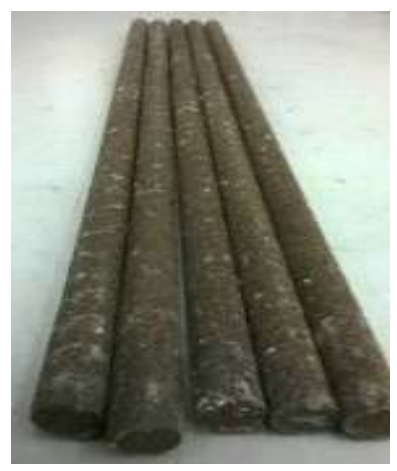

Fig.2. BFRP bars

and the length of chopped fiber (C). 6 groups of basalt chopped fiber reinforced RAC specimens were designed (specimens named K10-K15) for analyzing the bonding performance. And three groups of recycled concrete specimens without chopped fibers were designed (specimens named A16-A18) as the comparative group. The details of the specimens as shown in Table 6.

were measured and complete according to the Chinese code "Standard for test method of mechanical properties on ordinary concrete" (GB/T50081-2002) and the test results were showed in Table 6.

As the pull-out specimens with dimensions of $150 \times 150 \times 150 \mathrm{~mm}$, the diameter of BFRP bar was $16 \mathrm{~mm}$, and the length of bond zone [21] between BFRP reinforcement and RAC was $80 \mathrm{~mm}$ (five times the rebar diameter). A $70 \mathrm{~mm}$ PVC pipes was placed at the loading end to segregate RAC and BFRP bar. $20 \mathrm{~mm}$ BFRP bar was reserved at the free end of the cubic specimen in order to measure the relative slip to RAC and BFRP bar. The specimen details in the pull-out test were showed in Fig. 3. 


\subsection{Methods of Test}

The pull-out test is conducted under an electro-hydraulic servo testing machine of $300 \mathrm{kN}$ capacity. The test specimens were placed in a conventional tensile loading frame, as shown in Fig. 4. With the frame that two assembled steel plates (Brand 1045 in ASTM) in both ends with the thickness of $25 \mathrm{~mm}$ meet the requirements of Chinese standard "Concrete Test Method Standard Structure" (GB50152-2012). Note that the "loading end" refers to the location of the applied load and "free end" refers to the direction opposite to the load application. The load was applied by a force control method at a rate of $0.08 \mathrm{kN} / \mathrm{s}$. At the free end of BFRP bar, in order to measure the displacements within the range of $10 \mathrm{~mm}$ due to 4 linear variable differential transformer (LVDT) were installed, and an automatic data acquisition system was used to record the relevant data.

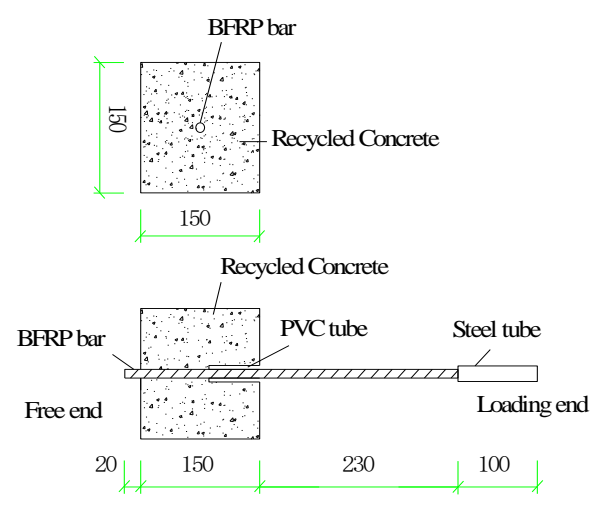

Fig. 3. Diagram of pull-out specimens (unit: $\mathrm{mm}$ )

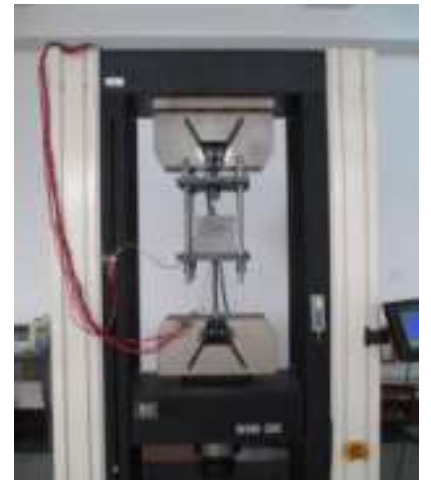

Fig. 4. Testing machine

\subsection{Test results}

The compressive strengths, splitting tensile strengths and axial compressive strengths of the specimens at 28 days are shown in Table 6.

Thus, the relationship of bond stress-slip with rebars and concrete was used to analyze the bond behavior of pullout test of BFRP bars and fiber RAC and was divided two modes (Table 6). The bond stress can be determined from the tensile pull-out load applied during the test. According to ACI 440.1R-06 [American Concrete Institute (ACI) 2006] the average bond stress ( $\mathrm{T}$ ) can be defined as:

$$
\tau=\frac{P}{\pi d l_{a}}
$$

Where $P$ is the tensile load, $d$ is the diameter of FRP bar, $l_{a}$ is the bond length (equal to $5 d$ ).

The results were shown in Table 6 .

Table 6

Test program and results

\begin{tabular}{cccccccccc}
\hline serial NO. & $\begin{array}{c}\text { Mix } \\
\text { design }\end{array}$ & $\begin{array}{c}\text { Volume } \\
\text { of } \\
\text { chopped } \\
\text { fiber }\end{array}$ & $\begin{array}{c}\text { Length of } \\
\text { chopped } \\
\text { fiber(mm }\end{array}$ & $\begin{array}{c}\text { Strength of } \\
\text { cube }\end{array}$ & $\begin{array}{c}\text { Strength } \\
\text { compressive } \\
\text { of }\end{array}$ & $\begin{array}{c}\text { Strength of } \\
\text { splitting } \\
\text { axial }\end{array}$ & $\begin{array}{c}\text { Ultimate } \\
\text { bond } \\
\text { compressive }\end{array}$ & $\begin{array}{c}\text { Slip of } \\
\text { strength } \\
\text { free } \\
\text { end }\end{array}$ & $\begin{array}{c}\text { Failure } \\
\text { modes }\end{array}$ \\
\hline K1 & C40 & 0.2 & 6 & 42.3 & 3.15 & 34.3 & 13.32 & 4.57 & $2 \mathrm{p} 1 \mathrm{~s}$ \\
K2 & C40 & 0.3 & 12 & 42.2 & 3.07 & 33.7 & 11.59 & 4.92 & $3 \mathrm{p} 0 \mathrm{~s}$ \\
K3 & C40 & 0.4 & 18 & 42.5 & 2.94 & 32.6 & 10.65 & 4.89 & $2 \mathrm{p} 1 \mathrm{~s}$ \\
K4 & C50 & 0.2 & 12 & 53.6 & 3.59 & 41.9 & 13.12 & 4.30 & $1 \mathrm{p} 2 \mathrm{~s}$ \\
K5 & $\mathrm{C} 50$ & 0.3 & 18 & 54.4 & 3.49 & 41.9 & 11.6 & 4.99 & $3 \mathrm{p} 0 \mathrm{~s}$ \\
\hline
\end{tabular}




\begin{tabular}{llllllllll}
\hline K6 & C50 & 0.4 & 6 & 50.1 & 3.43 & 42.1 & 12.22 & 4.26 & $3 \mathrm{p} 0 \mathrm{~s}$ \\
K7 & C60 & 0.2 & 18 & 60.9 & 3.99 & 57.6 & 17.36 & 2.67 & $2 \mathrm{p} 1 \mathrm{~s}$ \\
K8 & C60 & 0.3 & 6 & 62.5 & 4.04 & 57.8 & 14.88 & 5.79 & $2 \mathrm{p} 1 \mathrm{~s}$ \\
K9 & C60 & 0.4 & 12 & 61.2 & 3.86 & 51.0 & 13.97 & 3.77 & $3 \mathrm{p} 0 \mathrm{~s}$ \\
K10 & C40 & 0.2 & 18 & 42.5 & 3.18 & 33.8 & 11.11 & 3.47 & $3 \mathrm{p} 0 \mathrm{~s}$ \\
K11 & C50 & 0.2 & 18 & 55.5 & 3.6 & 43.7 & 14.81 & 4.92 & $3 \mathrm{p} 0 \mathrm{~s}$ \\
K12 & C60 & 0.4 & 6 & 63.9 & 4.14 & 52.9 & 13.63 & 3.69 & $3 \mathrm{p} 0 \mathrm{~s}$ \\
K13 & C60 & 0.4 & 18 & 58.5 & 3.58 & 49.1 & 12.29 & 4.80 & $2 \mathrm{p} 1 \mathrm{~s}$ \\
K14 & C50 & 0.2 & 6 & 51.7 & 3.57 & 40.2 & 13.84 & 3.13 & $2 \mathrm{p} 1 \mathrm{~s}$ \\
K15 & C50 & 0.3 & 6 & 52.7 & 3.61 & 42.6 & 12.83 & 3.54 & $3 \mathrm{p} 0 \mathrm{~s}$ \\
K16 & C40 & -- & -- & 41.9 & 2.88 & 32.1 & 13.28 & 2.08 & $3 \mathrm{p} 0 \mathrm{~s}$ \\
K17 & C50 & -- & -- & 52.8 & 3.3 & 40.3 & 13.84 & 4.18 & $2 \mathrm{p} 1 \mathrm{~s}$ \\
K18 & C60 & -- & -- & 61.2 & 3.89 & 52.5 & 13.2 & 3.39 & $2 \mathrm{p} 1 \mathrm{~s}$ \\
\hline
\end{tabular}

Failure modes: $p=$ pullout failure; $s=$ splitting failure; such as: $2 \mathrm{p} 1 \mathrm{~s}=$ pullout failure of two specimens and Splitting failure of one specimen. $\tau_{\max }, S_{\max }$ is the ultimate bond strength and maximum slip between free end of bars and the surface of concrete, respectively.

\section{Analysis of results}

\subsection{Failure mode}

Two types of failure mode for the specimens, pull-out damaged of BFRP bar and splitting failure of RAC, were observed in the experiment.

As the main failure mode of specimens in the test, pull-out failure mode was shown in Fig. 5a. At the initial of loading, bond-slip measured inapparent due to adhesive stress between BFRP bar and RAC was provided mainly by the chemical adhesion effect. The relative slip is not significant between the free end of BFRP bar and recycled concrete block. With the increasing of loading, the chemical adhesion had weakened gradually due to the growing slip between the BFRP bar and RAC matrix. Finally, the bond capacity was mainly attributed to the friction force until the BFRP bar was pulled out from the RAC block eventually, and serious damage could be observed on the surface of the bars.

In contrary, splitting failure mode could be observed in some specimens (see in Fig. 5b). At the Table 7 beginning of loading, it can be seen that splitting failure specimens when compared with pull-out failure ones were similar. And then, while the load was closed to the ultimately, tiny cracks could be clearly seen on the upper surface of specimens, and accompany by a slight cracking sound. As the result, the specimen cracked along the direction of bar and the block was divided into two or more pieces by the star-ray style crack. At last, the specimen was splitting suddenly with brittleness characteristic. (a)

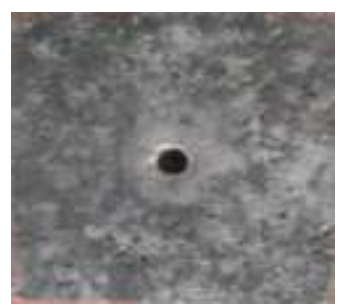

(b)

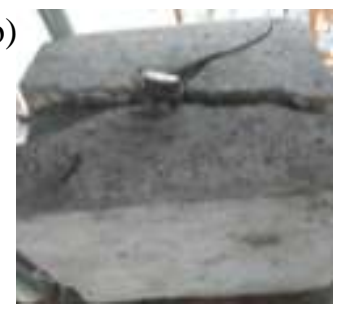

Fig.5. Failure pattern:(a) pull-out failure; (b) splitting failure

\subsection{Range analysis}

Based on the orthogonal test method, influence of the recycled concrete strength, content of basalt fiber and the length of chopped fiber respectively to the bonding performance were analyzed. In addition, the value of range $(\mathrm{R})$ which indicated the degree of impaction of the factors on the mechanical and bond behaviors of the specimens were listed see in Table 7 .

Range analysis 


\begin{tabular}{cccc}
\hline & $\begin{array}{c}\text { Grade of recycled concrete } \\
\text { (A) }\end{array}$ & $\begin{array}{c}\text { Content of } \\
\text { basalt fiber (B) }\end{array}$ & $\begin{array}{c}\text { Length of Chopped strand } \\
\text { fiber(C) }\end{array}$ \\
\hline $\begin{array}{c}\text { Compressive strength of cube } \\
\text { Strength of Splitting and tensile }\end{array}$ & 19.1 & 1.9 & 1.54 \\
Compressive strength of Axial & 0.87 & 0.23 & 0.19 \\
Ultimate bond strength & 20.18 & 5.34 & 2.78 \\
Slippage of free end & 2.23 & 1.43 & 0.50 \\
\hline
\end{tabular}

From Table 7 it was known that the value of parameter A was the biggest in the three parameters, that concluding compressive strength of cube, strength of splitting and tensile, compressive strength of axial and ultimate bond strength. This indicated that, the strength of RAC mostly affected in the three mechanical behaviors and ultimate bond strength among the parameters. Similarly, the slippage of free end was affected by the content of basalt fiber among the three parameters that was the most. Compared to the influence of RAC, bond strength of basalt fiber bars in basalt fiber concrete could limit the contraction of concrete, contraction decreasing of concrete decreased the bond stress with basalt FRP bars. The order of the parameters affected the property of mechanical of recycled concrete and the ultimate performance of bond was B (content of basalt fiber)> A (strength grade of recycled concrete) $>\mathrm{C}$ (length of chopped strand fiber). Simultaneously, for the slippage of free end, the order changed to B (content of basalt fiber)> A (strength grade of recycled concrete) $>\mathrm{C}$ (length of chopped strand fiber).

As shown in Table 6, It also could be found that, on one hand, the fiber was the main contributor to the bond performance. To balance of the beneficial and adverse effect of fiber and the improvement of bond grade, thus the bond stress of RAC bonding was the best under a fiber volume content of $0.2 \%$ and increased with the level of RAC increasing [22], so the best combination was $\mathrm{A} 3 \mathrm{~B} 1 \mathrm{C} 3$; On the other hand, in terms of the slippage, when the content of fiber was $0.3 \%$ with the length of $6 \mathrm{~mm}$ for RAC by mix 3 , the amount of slip of free end achieved the maximum.

\subsection{Analysis of bond stress-slip relationship}

According to Eq.(1), the bond stress between BFRP bar and RAC could be converted by the loading force. Fig. 6a, Fig. $6 \mathrm{~b}$ and Fig. $6 \mathrm{c}$ were the bond-slip curves of RAC specimens with and without fiber under different conditions.

(1) The effect of recycled concrete strength

In this section, the experimental results on bond-slip curves from the three different target concrete compressive strengths (C40, C50 and C60) were analyzed. As shown in Figure 6a, specimens (K10, K11, K7) incorporated with $18 \mathrm{~mm}$-length fiber at $0.2 \%$ volume content for different RAC strength were selected to study the varies regulation. From the curves of K10, K11, K7 it was said that, strength of ultimate bond increasing with the increase of RAC grade. The increase amplitude decreased with the increase of RAC strength, especially when the RAC grade was $\mathrm{C} 60$ the peak bond stress seemed inapparent chang. In addition, compared with the maximum slips of the specimens with fiber were greater than the specimens without fiber and the scope of increasing was $17.7 \%$ to $66.8 \%$.

The study showed that basalt chopped fiber have the capacity to enhance the cracking resistance ability of concrete, it will prevent shrinkage of concrete [23] and that closed to the BFRP bar leaded to a declination of the wrapping force of concrete, which reducing the friction and bonding strength between bars fiber and the matrix.

Due to the existing of basalt chopped fiber, development of crack inner concrete was delayed and the splitting strength of RAC specimen was greater than that of specimen without fiber. So that the maximum slippage of fiber reinforced RAC specimen 
was greater than the specimens non-incorporated fiber, and the slope of down segment for the RAC specimen decreased with the incorporation of the fibers.

\section{(2) The influence of fiber volume content}

In Fig. 6b, compared the relationship between the bond-slip curves in three groups that had the same concrete grade (C50), fiber length $(6 \mathrm{~mm})$ and three different volume fiber content $\quad(0.2 \%, 0.3 \%, 0.4 \%)$ at the influence of bonding strength and slip. For specimen K14 (0.2\%), K15 (0.3\%), and K6 (0.4\%), in one hand, the ultimate bonding strength decreased with the increasing of the fiber content. In another hand, the maximum slips were also increased with increasing of the fiber volume content, the scope of reducing was $20.1 \%-36.1 \%$. Simultaneously, the bond strength was decreased compared the RAC specimen without fiber (K17) with the incorporating of chopped basalt fiber and the maximum slip was increased. The investigations reveal that the ductility of the specimen

(a)

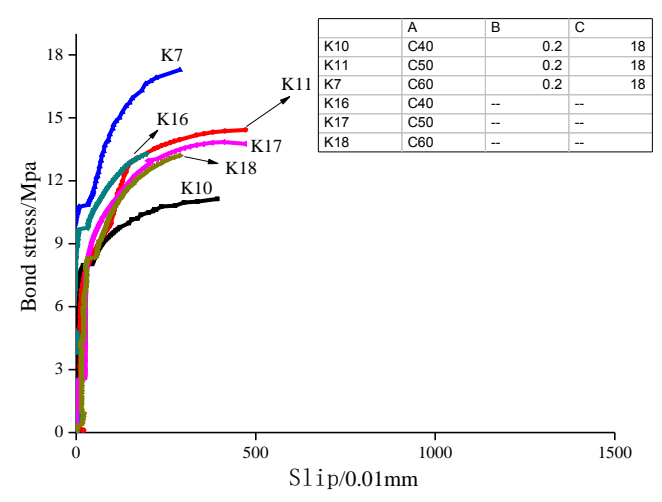

was improved due to the contribution of fibers bridging the crack although decreased the bond strength of these specimens.

(3) The influence of length of fiber

Bond-slip curves for three different fiber length specimens(K12, K9, K13) were shown in Fig. 6c. Test results showed that the ultimate bond strength was decreased and the value of maximum slip was increased with the increasing of fiber length. While, to compare the RAC specimen (K18) without fiber and the fiber RAC specimens (K12, K9, K13), not only the ultimate bond strength of the fiber RAC specimens higher than specimen K18 except K13, but also slip amount of the fiber RAC specimens increased as well. As a result, it would appear that control the length of the fiber reasonably could improving the bond stress of fiber RAC and BFRP bars effectively due to increase the ductility of the concrete matrix [24-25].

(b)

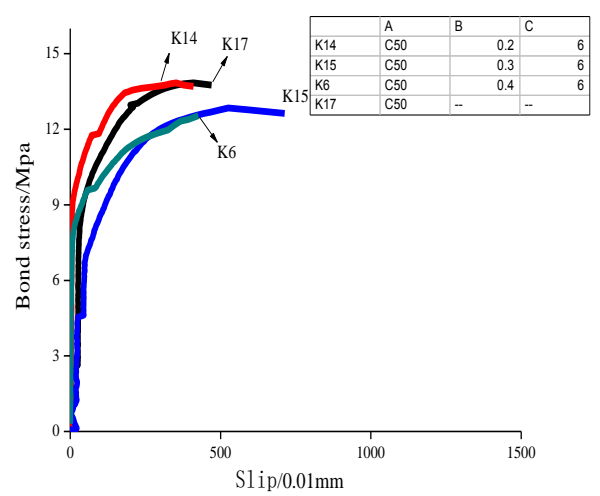

(c)

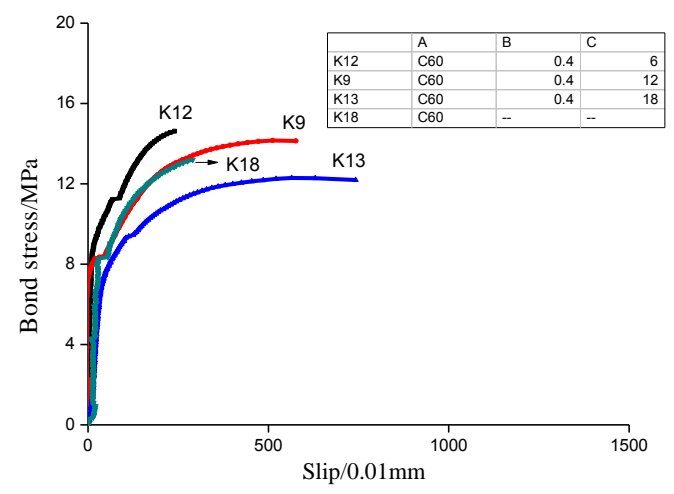

Fig.6. The bond stress - slip curve: (a) different strength specimens of recycled concrete; (b) different volume content of fiber specimen; (c) different length of fiber specimen.

\section{The regression model of bond stress - slip}

According to the studied method of literature 
[26-27], the effect of these multiple factors to the target property was analyzed. The bond stress of specimens could be obtained by nonlinear regression analysis, and the regression equation was :

$$
\begin{array}{rr}
Y=6.9098+0.1316 X_{1}-75.6202 X_{2}-23353.3 X_{2}{ }^{2}+0.239 X_{3} \\
-0.00315 X_{3}{ }^{2}-66.727 X_{2} X_{3}
\end{array}
$$

where $X_{1}$ is RAC strength, $X_{2}$ and $X_{3}$ are the volume content and length of fiber.

In Eq.(2), on one hand, the coefficients of one degree term $X_{1}$ and $X_{3}$ were positive which indicated that the strength of RAC increasing could promote the bond stress between the RAC and BFRP bars, coefficient of one degree term $\mathrm{X}_{2}$ was negative which indicated the fiber volume content involved in decreasing the enhanced of bond strength of specimens. On the other hand, the more the fiber volume content the lower bond strength, the longer fiber length the lower bond strength, by the coefficients of quadratic term $X_{2}$ and $X_{3}$ were negative. In addition, regression results with the interaction terms of $X_{2}$ and $X_{3}$ was negative which indicated that produced negative effects with the interaction effect of fiber volume content and fiber length. The ultimate bond strength obtained by fitting analysis and the experiment were listed in Table 8.

\section{Table 8}

Fitting value comparison with the experimental value of bond strength

\begin{tabular}{cccc}
\hline Test No. & Fitted values & Test values & Test value/Fitted values \\
\hline K1 & 12.44722 & 13.32 & 1.070118 \\
K2 & 11.74539 & 11.59 & 0.98677 \\
K3 & 9.969322 & 10.65 & 1.068277 \\
K4 & 12.80297 & 13.12 & 0.867767 \\
K5 & 12.1738 & 11.6 & 1.090867 \\
K6 & 14.0545 & 12.22 & 0.933509 \\
K7 & 12.7255 & 17.36 & 0.911555 \\
K8 & 12.53102 & 14.88 & 0.97518 \\
K9 & 14.11897 & 13.97 & 1.048943 \\
K10 & 13.76322 & 11.11 & 1.005578 \\
K11 & 13.17047 & 14.81 & 0.974149 \\
K12 & 13.4898 & 13.63 & 1.02596 \\
K13 & 15.43497 & 12.29 & 1.124718 \\
K14 & 14.48647 & 13.84 & 1.027165 \\
K15 & 13.33757 & 12.83 & 1.047417 \\
K16 & 13.84702 & 13.28 & 0.984327 \\
K17 & 12.60132 & 13.84 & 0.975294 \\
K18 & 14.8058 & 13.2 & 0.891543 \\
\hline
\end{tabular}

It can be concluded from Table 8 that, ultimate bond strength values calculated from the regression equation fit well with the experimental results, in addition, their ratios had a smaller gap and the range of the fluctuation was $0.6 \%-13.3 \%$. Tab.8 also indicated that, Eq.2 was not only fit well for RAC specimens with chopped fiber, but also well for RAC specimens without fibers.

\section{Conclusion}

In this paper, the effect of including chopped fiber on the mechanical properties and bond behavior between BFRP bars and RAC was investigated with a total of 54 specimens for pull-out test and 162 specimens for mechanical properties. Based on the experimental results and discussion the following conclusions can be drawn:

(1) Based on the bond strength of basalt fiber bars in basalt fiber concrete could limit the contraction of concrete, contraction decreasing of concrete decreased 
the bond stress with basalt FRP bars. The strength of RAC was the main influence factor to the compressive strength of cube, strength of splitting and tensile, compressive strength of axial and ultimate bond strength. Meanwhile, the content of basalt fiber had the greatest impact on the slippage of free end among the three influence factors. The sequence of the influence factors that affected the mechanical property indicators of concrete regeneration and ultimate performance of bond was: $\mathrm{A}>\mathrm{B}>\mathrm{C}$. And the sequence on the slip amount of free end was: $B>A>C$.

(2) An increase in ultimate bond strength was observed with increasing of recycled concrete and the maximum increasement rate was $56.3 \%$. While, an decrease in bond strength occurred when the chopped fiber was incorporated into the RAC specimens. Furthermore, the bond strength was decreased with the increasing of fiber volume content. Experimental results confirm the tendency of the ductility of RAC specimens by incorporating chopped fiber with an proper fiber length and RAC grade.

(3) With the increasing of RAC strength, the maximum slip value of BFRP bar and RAC was increased, and the situation was more obvious in the specimens with chopped fiber compared with the without fiber ones. With the increase of the fiber volume content, the maximum slip increased as well. With the incorporation of chopped fiber, the slope of decreasing segment in bond-slip curves decreased. With the increase of fiber length, the maximum slip gradually increased, compared to specimens of non-doped fiber recycled concrete.

(4) An equation was proposed to predict the ultimate bond strength for RAC specimens (both for with and without chopped fiber) reinforced with BFRP bars. Due to the limit of the small amount of data available on this topic, this equation could be modified with further study.

\section{Acknowledgements}

This work was supported by Program for Liaoning Provincial Natural Science Foundation of China: Grants: 2015020208 and 2015020214, the National Natural Science Foundation of China: Grant:
11302093, and the National Science Foundation of China: Grant: 51479168.

\section{References}

[1] Heede PVD, Belie ND. Environmental impact and life cycle assessment (LCA) of traditional and 'green' concretes: Literature review and theoretical calculations. Cement and Concrete Composites 2012; 34(4): 431-442.

[2] Faleschini F, Zanini MA, Pellegrino C, Pasinato S. Sustainable management and supply of natural and recycled aggregates in a medium-size integrated plant. Waste Management 2016; 49:146-155.

[3] Blengini GA, Garbarino E. Resources and waste management in Turin (Italy): the role of recycled aggregates in the sustainable supply mix. Journal of Cleaner Production 2010; 18(10-11):1021-1030.

[4] Lin X, Zhang Y. Bond-slip behaviour of FRP-reinforced concrete beams. Construct Build Mater 2013; 44: 110-117.

[5] Aiello MA, Leone M, Ombres L. Modeling of the behavior of concrete tension members reinforced with FRP rods. Mech Compos Mater 2003; 39(4): 283-292.

[6] Micelli F, Nanni A. Tensile characterization of FRP rods for reinforced concrete structures. Mech Compos Mater 2003; 39(4): 293-304.

[7] Dong J, Hou M, Wang Q, Zhang D. The basic mechanical properties of basalt fiber recycled concrete. Journal of Sichuan University: Engineering Science 2012; S2: 9-12.

[8] Xue W, Liu H, Wang X. Studies on bond properties of new-type FRP bars. Journal of Building Structures 2004; 25(2): 104-109,123.

[9] Shang H. Foreign research and application of FRP reinforcement. Building Technique Development 2012; 8: 96-98.

[10] Pleimann LG. Strength, modulus of elasticity, and bond of deformed FRP rods. Adv Compos Mater Civ Eng Struct 1991: 99-110. 
[11] Ehsani MR, Saadatmanesh H, Tao S. Design recommendations for bond of GFRP rebars to concrete. J Struct Eng 1996; 122(3): 247-254.

[12] Okelo R, Yuan RL. Bond strength of fiber reinforced polymer rebars in normal strength concrete. J Compos Construct 2005; 9(3): 203-213.

[13] Xu L, Chen P, Huang L, Zhang A, Li B. Experimental research on bond properties between hybrid steel-polypropylene fiber reinforced concrete and deformed bar. China Civil Engineering Journal 2015; (4): 15-22.

[14] Xue W, Fang Z, Wang Y, Kang M. Bond strength of AFRP rebars in concrete. $\mathrm{J}$ Build Mater 2015(03).

[15] Yaz S, Arel HS. The effect of steel fiber on the bond between concrete and deformed steel bar in SFRCs. Construct Build Mater 2013; 40(3): 299-305.

[16] Mazaheripour H, Barros J, Sena-Cruz JM, Pepe M, Matinelli E. Experimental study on bond performance of GFRP bars in self-compacting steel fiber reinforced concrete. Compos Struct 2013; 95:201-212.

[17] Ganesan N, Indira PV, Sabeena MV. Bond stress slip response of bars embedded in hybrid fibre reinforced high performance concrete. Construct Build Mater 2014; 50:108-115.

[18] Baena M, Torres L, Turon A, Llorens M, Barris C. Bond behaviour between recycled aggregate concrete and glass fibre reinforced polymer bars. Construct Build Mater 2016; 106: 449-460.

[19] Kim HJ, Sim J. Mechanical properties of GFRP slip-form for in-situ application. KSCE J Civ Eng 2015: 1-10.

[20] Achillides Z, Pilakoutas K. Bond behavior of fiber reinforced polymer bars under direct pullout conditions. J Compos Construct 2004; 8(2): 173-181.

[21] Ding Y, Ning X, Zhang Y, Pacheco-Torgal F, Aguiar JB. Fibres for enhancing of the bond capacity between GFRP rebar and concrete. Construct Build Mater 2014; 51: 303-312.

[22] $\mathrm{Hu} \mathrm{X}, \mathrm{Zhu} \mathrm{H}$. Effects of adding basalt fiber on bond properties between deformed bar and concrete. Industual Constuction 2013; 03: 84-87.

[23] D' Antino T, Pellegrino C. Bond between FRP composites and concrete: assessment of design procedures and analytical models. Compos B: Eng 2014; 60: 440-456.

[24] Sim J, Park C. Characteristics of basalt fiber as a strengthening material for concrete structures. Compos B: Eng 2005; 36(6): 504-512.
[25] Söylev TA. The effect of fibers on the variation of bond between steel reinforcement and concrete with casting position. Construct Build Mater 2011; 25(4): 1736-1746.

[26] Gong J, Shi P, Li C. Application of excel software in multi-nonlinear regress analysis. Agriculture Network Information 2011(1): 46-48.

[27] Wang R, Dong X, He W. A method of multivariate nonlinear regression model and its application. China Examinations 2010(11): 17-22. 